\title{
Functional Studies in Patients with the Glucagonoma Syndrome
}

\author{
J. J. Holst, S. Helland ${ }^{4}$, S. Ingemannson ${ }^{3}$, N. Bang Pedersen ${ }^{2}$, and H. von Schenck ${ }^{1}$ \\ Department of Clinical Chemistry, Bispebjerg Hospital, and Institute of Medical Physiology C, University of Copenhagen, Copenhagen, \\ Denmark; Departments of ${ }^{2}$ Dermatology and ${ }^{3}$ Surgery, University Hospital, Lund, and ${ }^{1}$ Department of Clinical Chemistry, Regional \\ Hospital, Linköping, Sweden; and Department of Dermatology, ${ }^{4}$ Haukeland Hospital, Bergen, Norway
}

Summary. Four patients with glucagon-producing tumours of the pancreas were investigated. Fasting plasma glucagon concentrations ranged from 209-625 pmol/l. Plasma insulin concentrations were normal except in one patient, where the tumour also produced insulin $(558 \mathrm{pmol} / 1)$. Intravenous glucose $\left(25 \mathrm{~g} / \mathrm{m}^{2}\right)$ depressed the glucagon concentration in two patients, while no change was noted in the others. Intravenous arginine stimulated glucagon secretion in three patients, but not in the fourth. Intravenous somatostatin suppressed glucagon secretion in all three patients investigated. All patients had abnormally low plasma levels of individual amino acids; glucogenic and branched-chain amino acids were equally depressed. Surgical removal of the tumours led to complete recovery from dermatosis and the glucagon levels were normalized. Postoperative tests were performed in three patients. The $\alpha$ cell responsiveness to iv glucose was restored. Glucose tolerance (Kg-value) was improved in one patient $(0.73$ to 1.65$)$, persistently low in one patient ( 0.75 to 0.72$)$ and impaired in the third patient ( 1.35 to 1.09). It is concluded that none of these functional tests will be of diagnostic value in cases suspected of glucagonomas. The results also show that glucose homeostasis is remarkably unaffected by the extreme hyperglucagonaemia of these patients and that hypoaminoacidaemia is an important consequence of chronic hyperglucagonaemia.

Key words: Glucagon, insulin, endocrine tumours, islet cell tumours, somatostatin, necrolytic migratory erythema, hyperglucagonaemia, glucose tolerance, plasma amino acids, glucagonoma.
The first proven case of a glucagon-producing tumour was reported by McGavran and associates in 1966 [1]. Such tumours were considered to be extremely rare, until Mallinson et al. in 1974 collected nine similar cases, and brought attention to the association between glucagon-producing tumours of the pancreas and the peculiar dermatosis, the necrolytic migratory erythema [2]. This syndrome - the glucagonoma syndrome - has since been recognized in increasing numbers [3-5]. Few reports have dealt with functional diagnostic tests in these patients $[6$, 7]. The present report contains the results of such studies in four patients, who all suffered from a typical glucagonoma syndrome, and who were all successfully operated upon for glucagon-producing tumours.

\section{Material and Methods}

The dermatosis and the clinical course of patients 1,2 and 4 have been described in detail $[8,9,10]$ and patient 3 exhibited essentially the same features. All suffered from necrolytic migratory erythema $[11,12]$ for several years, and experienced weight loss, elevated erythrocyte sedimentation rate, anaemia, and hyperglucagonaemia (case 1, 226 pmol/1; case $2,560 \mathrm{pmol} / 1$; case 3 , $441 \mathrm{pmol} / 1$; and case 4, $329 \mathrm{pmol} / 1$; fasting values, upper normal limit, $35 \mathrm{pmol} / \mathrm{l})$.

The four patients ( 3 males, age 69, 67 and 62 years and one female, age $46 \mathrm{a}$; \% ideal body weight: $94,78,115$, and 96 , respectively) underwent intravenous glucose tolerance tests $\left(25 \mathrm{~g} / \mathrm{m}^{2}\right.$ body surface over $4 \mathrm{~min}$ ) and an arginine infusion test (arginine$\mathrm{HCl}$ infused as a $10 \mathrm{~g} / 100 \mathrm{ml}$ solution, $0.5 \mathrm{~g} / \mathrm{kg}$ over $30 \mathrm{~min}$ ). Patients 2-4 also received somatostatin, $250 \mu \mathrm{g}$ as a bolus, and $750 \mu \mathrm{g}$ as a constant infusion over $60 \mathrm{~min}$. Patients 1 and 4 had a glucagon test ( $1 \mathrm{mg}$ glucagon, NOVO, iv) and patient 2 had an insulin tolerance test $(0.1 \mathrm{U} / \mathrm{kg} \mathrm{MC}$-insulin, NOVO, iv). From patient 3 , blood samples were obtained 3 times a day, the first bcing obtained in the fasting state, over 5 consecutive days.

The samples were analysed for blood glucose [13] and plasma 

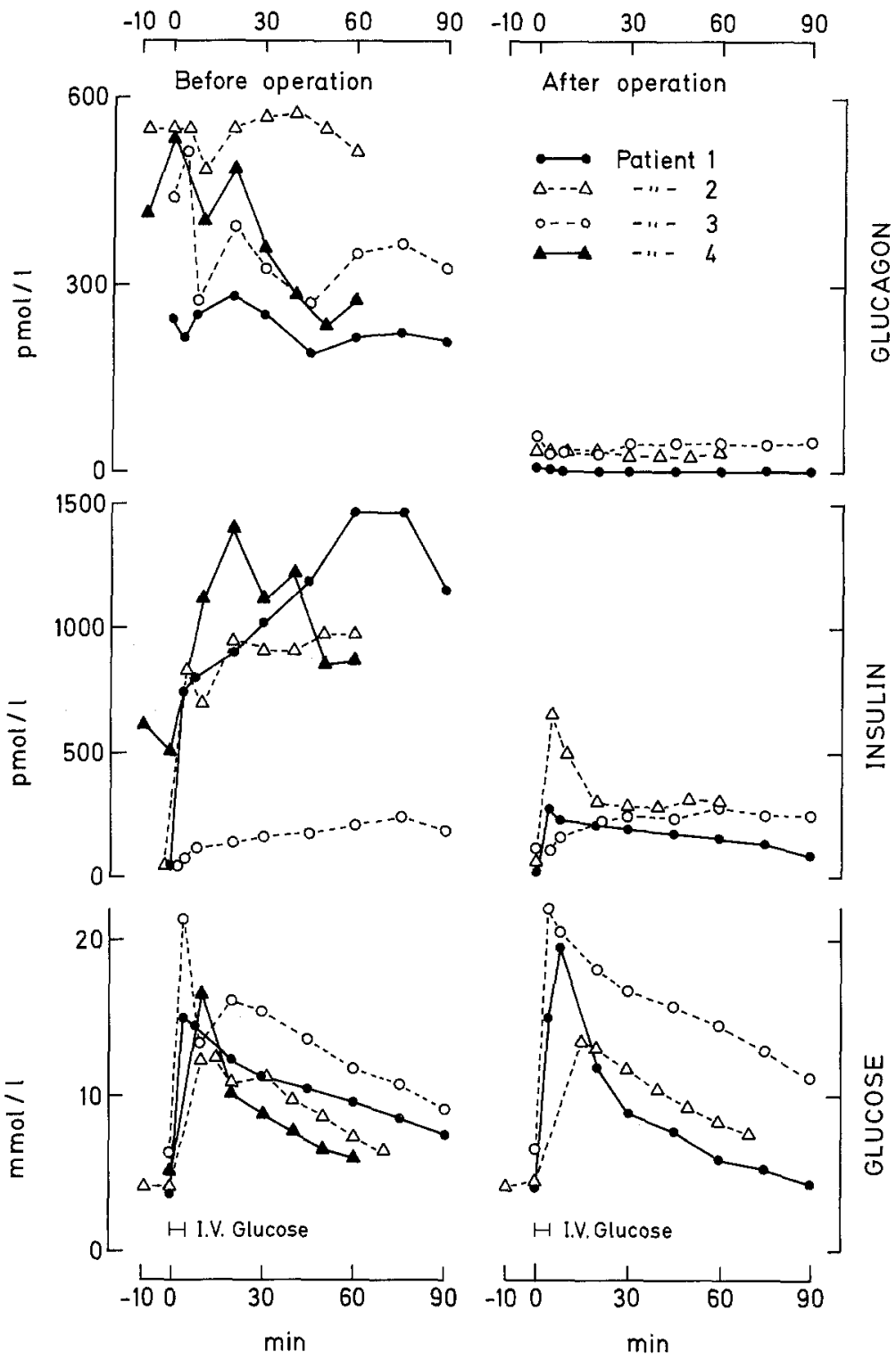

Fig. 1. Glucagon, insulin and glucose concentrations in plasma and blood of four glucagonoma patients in response to an intravenous glucose tolerance test before (left panel) and after (right panel) surgical removal of the tumour

concentrations of insulin and glucagon as previously described [13, $14,15,16]$. The antibodies used for radioimmunoassay of glucagon were directed against the C-terminal sequence of the glucagon molecule and did not crossreact with gut glucagons. By gel filtration on Sephadex G50 it was established that the hyperglucagonaemia was not due to immunoreactivity which coeluted with proteins in the void volume (Big plasma glucagon [17]) but to components with elution characteristics corresponding to those of glucagon and so-called "proglucagon" $[5,9]$.

The concentrations of individual amino acids in the basal state from each of the patients were determined by automated ionic exchange chromatography. The following laboratories performed the analyses: Medicinsk Laboratorium Ltd, Copenhagen, Denmark; department of clinical chemistry, University Hospital of Lund, Sweden, and department of clinical chemistry, General Hospital in Malmö, Sweden; department of clinical chemistry, Dikemarck Hospital, Norway. The normal ranges given in table 2 represent the extremes of the (very similar) normal ranges from each of the four laboratories.
In patients 1,3 , and 4 the exact localisation of the glucagonproducing tumours was determined by selective pancreatic vein catherisation and preoperative hormone analyses (see 10,18, and 19 for detailed description). In patients 1 and 2 a tumour was found in the tail of the pancreas, and hemipancreatectomy performed. The tumours of patients 3 and 4 were located in the head of the pancreas and could be enucleated. Two to six months after the operation the glucose tolerance test and the amino acid infusions were repeated in three and two of the patients, respectively. The insulin test was repeated in patient 2.

The pathology of the tumours has been described previously $[9$, $10,19]$. They consisted mainly of glucagon-producing $\alpha$-cells although all were mixed. The tumour of patient 4 contained a large number of insulin-producing cells, and several cells which contained serotonin. The glucagon content of the tumours of patients 1 and 3 (measured radioimmunologically after acid-ethanolextraction) was 23 and $2.9 \mathrm{nmol} / \mathrm{g}$ tumour (wet weight) both well above the glucagon concentration in normal pancreases obtained at autopsy (approximately $1 \mathrm{nmol} / \mathrm{g}$ ). 


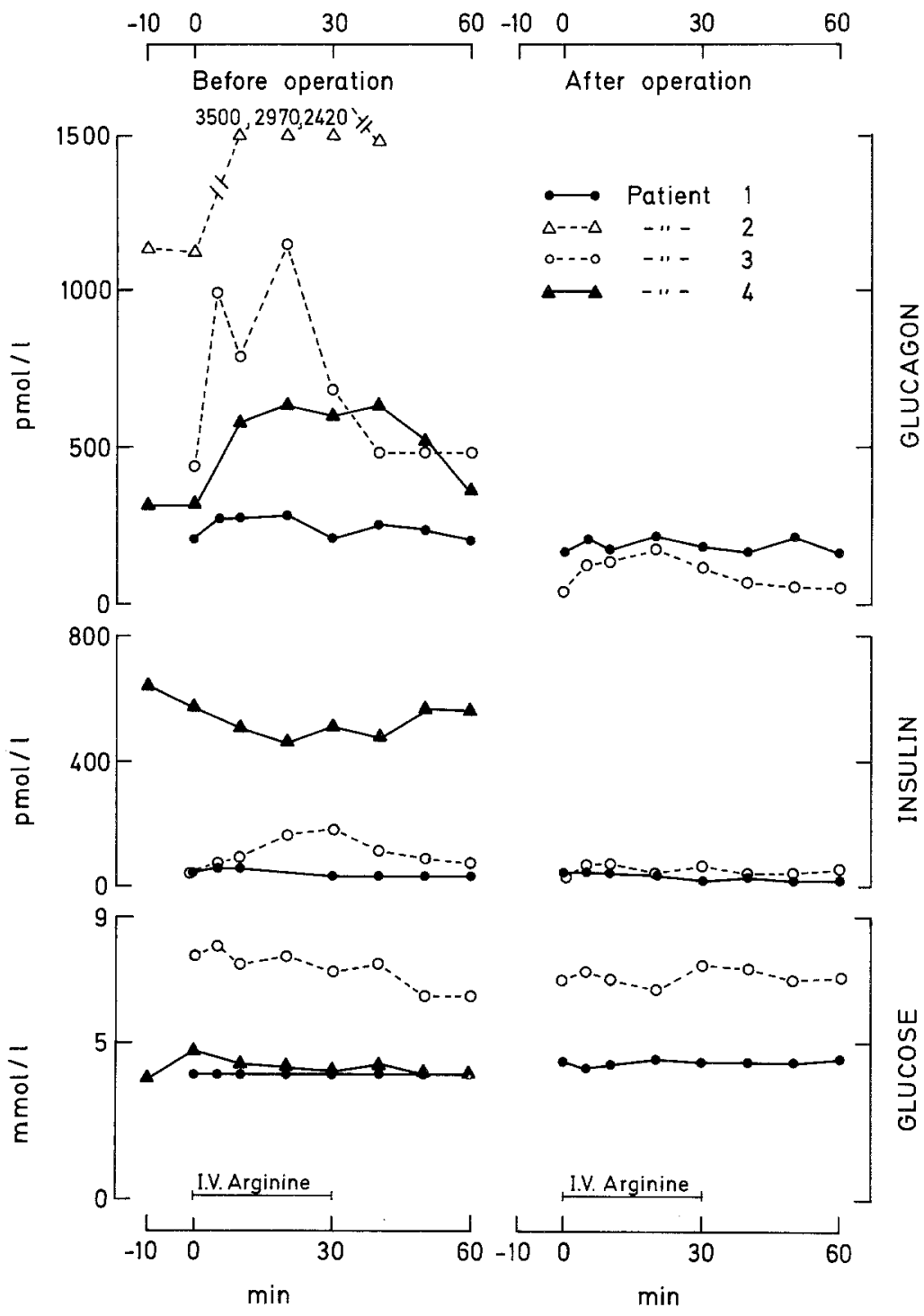

Fig. 2. Glucagon, insulin and glucose concentrations in plasma and blood of four glucagonoma patients (patient 2 had only glucagon determinations) in response to an arginine infusion before (left panel) and after (right panel; only patients 1 and 3 were investigated after operation) surgical removal of the tumour

\section{Results}

\section{Before Operation}

Fasting blood glucose concentrations (median and range of 3-5 determinations on separate days) in patients $1-4$ were $3.7(3.7-4.0), 4.1$ (3.8-4.2), 7.4 (6.4-7.8) and 4.8 (3.5-5.0) $\mathrm{mmol} / 1$ respectively. Under similar conditions, fasting plasma glucagon concentrations were 226 (209-243), 560 (550-625), 441 (430-447) and 329 (319-485) pmol/l respectively. Fasting plasma insulin levels were 42,70 (63-116), 56 (49-77) and 558 (448-558) pmol/1 respectively. The results of the IVGTT are shown in Fig. 1. The glucose assimilation constants $\left(\mathrm{K}_{\mathrm{g}}\right)$ [20] were $0.73,1.35,0.75$, and 1.42 per cent $\mathrm{x} \mathrm{min}{ }^{-1}$, respectively. The plasma glucagon concentrations in patients 1 and 2 remained unchanged during the IVGTT, whereas a decrease was noted in patients 3 and 4 . Insulin secretion was strongly stimulated in patients 1,2 and 4 , and weakly stimulated in patient 3 .

The results of the arginine infusion tests are shown in Fig. 2 (in patient 2 only glucagon was measured). Arginine stimulated glucagon secretion strongly in patients $2-4$, but was without effect on glucagon secretion in patient 1 .

The somatostatin infusions performed in patients 2-4 (Table 1) dramatically suppressed plasma glucagon and insulin concentrations. In two patients glucose concentrations were depressed. 
Table 1. Somatostatin infusion test in 3 glucagonoma patients

\begin{tabular}{|c|c|c|c|c|c|c|c|c|c|c|}
\hline \multicolumn{4}{|c|}{ Patient no. 3} & \multicolumn{4}{|c|}{ Patient no. 2} & \multicolumn{3}{|c|}{ Patient no. 4} \\
\hline $\begin{array}{l}\text { Sampling } \\
\text { time min }\end{array}$ & $\begin{array}{l}\text { Glucagon } \\
\mathrm{pmol} / 1\end{array}$ & $\begin{array}{l}\text { Insulin } \\
\mathrm{pmol} / \mathrm{l}\end{array}$ & $\begin{array}{l}\text { Glucose } \\
\mathrm{mmol} / \mathrm{l}\end{array}$ & $\begin{array}{l}\text { Sampling } \\
\text { time min }\end{array}$ & $\begin{array}{l}\text { Glucagon } \\
\mathrm{pmol} / \mathrm{l}\end{array}$ & $\begin{array}{l}\text { Insulin } \\
\mathrm{pmol} / 1\end{array}$ & $\begin{array}{l}\text { Glucose } \\
\mathrm{mmol} / 1\end{array}$ & $\begin{array}{l}\text { Glucagon } \\
\mathrm{pmol} / 1\end{array}$ & $\begin{array}{l}\text { Insulin } \\
\mathrm{pmol} / 1\end{array}$ & $\begin{array}{l}\text { Glucose } \\
\text { mmol/1 }\end{array}$ \\
\hline-20 & 444 & 77 & 7.4 & -10 & 570 & 126 & 4.3 & 319 & 520 & 2.9 \\
\hline-10 & 430 & 70 & 7.4 & 0 & 550 & 105 & 4.1 & 339 & 455 & 3.5 \\
\hline 0 & 401 & 84 & 7.2 & 5 & 370 & 70 & 3.4 & 365 & 445 & 3.2 \\
\hline 10 & 172 & 35 & 7.2 & 10 & 400 & 42 & 3.5 & 47 & 260 & 3.1 \\
\hline 20 & 109 & 28 & 7.2 & 20 & 255 & 28 & 3.6 & 53 & 300 & 2.0 \\
\hline 30 & $<28$ & 14 & 7.5 & 30 & 255 & 21 & 3.2 & 68 & 280 & 2.2 \\
\hline 40 & $<28$ & 21 & 7.4 & 40 & 200 & 35 & 2.9 & 107 & 300 & 2.5 \\
\hline 50 & 52 & 28 & 6.6 & 60 & 200 & 28 & 2.6 & 146 & 335 & 2.8 \\
\hline 60 & 143 & 35 & 7.2 & 90 & 200 & 7 & 2.6 & 149 & 390 & 4.2 \\
\hline
\end{tabular}

Patients no. 3 and 4 received synthetic linear somatostatin (Ferring, Sweden), and patient no. 2 synthetic cyclic somatostatin (Kabi, Stockholm, Sweden), $250 \mu \mathrm{g}$ as a bolus at " 0 " minutes and $750 \mu \mathrm{g}$ as a constant infusion for 60 minutes

Table 2. Amino acids $(\mu \mathrm{mol} / \mathrm{l})$ in plasma from 4 glucagonoma patients

\begin{tabular}{lccccc}
\hline & \multicolumn{5}{c}{ Patient } \\
\cline { 3 - 6 } Amino acid & Normal range & 1 & 2 & 3 & 4 \\
\hline Alanine & $(200-550)$ & 106 & 67 & 108 & 42 \\
Arginine & $(65-140)$ & 36 & traces & 49 & n. d. \\
Ornithine & $(20-90)$ & - & 6 & 33 & 5 \\
Citrulline & $(15-60)$ & - & traces & 8 & 3 \\
Aspartic acid & $(0-11)$ & - & - & 13 & n.d. \\
Asparagine & $(44-70)$ & - & 21 & - & 9 \\
1/2 cystine & $(38-160)$ & 15 & traces & n. d. & n.d. \\
Glutamic acid & $(11-190)$ & 34 & 31 & 81 & 4 \\
Glutamine & $(420-750)$ & 176 & 133 & 39 & 134 \\
Glycine & $(179-520)$ & 123 & 68 & 102 & 69 \\
Histidine & $(51-97)$ & 22 & 34 & 39 & - \\
Methionine & $(18-30)$ & 39 & traces & 8 & traces \\
Proline & $(75-290)$ & 32 & 20 & - & n. d. \\
Serine & $(70-180)$ & 53 & 51 & 66 & 17 \\
Threonine & $(75-230)$ & 26 & 23 & 33 & 2 \\
Tryptophane & $(21-39)$ & - & - & - & 23 \\
Valine & $(160-317)$ & 87 & 74 & 82 & n. d. \\
Leucine & $(80-176)$ & 46 & 47 & 57 & 61 \\
Isoleucine & $(40-99)$ & 76 & 24 & 30 & 22 \\
Lysine & $(150-218)$ & 40 & 47 & 75 & 71 \\
Phenylalanine & $(42-70)$ & 41 & 35 & 29 & 39 \\
Tyrosine & $(40-90)$ & - & 18 & 20 & 18 \\
- & & & & \\
\hline
\end{tabular}

n. d. = not detectable

The effect of $1 \mathrm{mg}$ of glucagon injected intravenously was investigated in patients 1 and 4 . Both responded with an increase in blood glucose to 60 and $42 \%$ above basal, respectively, the peak value being reached $30 \mathrm{~min}$ after the injection. An insulin tolerance test was performed in patient 2 , in spite of glucose concentrations of $1.8 \mathrm{mmol} / 160 \mathrm{~min}$ after the injection, there was no increase in glucagon concentration.

In patient 3 the concentrations of glucagon, insulin, and glucose were measured in the overnight fasting state and after a meal for 5 consecutive days.
Glucagon concentrations varied between 413-819 pmol/1, insulin concentrations between $49-126 \mathrm{pmol} / \mathrm{l}$, and glucose between $3.6-8.4 \mathrm{mmol} /$ 1 , but there was no regular pattern and the insulin and glucose concentrations could not be related to variations in glucagon concentration.

In patients $2-4 \mathrm{Zn}^{++}$and $\mathrm{Cu}^{++}$(only patient 3 ) concentrations in blood and urine were determined. The results were within the normal range.

The concentrations of individual amino acids in plasma obtained in the fasting state are shown in Table 2. The concentrations of glucogenic, ketogenic (leucine) as well as the combined glucogenic and ketogenic amino acids were all very low. The important glucogenic amino acids alanine and glutamine were both extremely low in all patients.

\section{After Operation}

After recovery, which was uneventful in all cases and led to complete cure of the skin disease, some of the above tests were repeated (Figs. 1 and 2). In patient 1 glucose tolerance had improved $\left(\mathrm{K}_{\mathrm{g}}=1.65\right)$, plasma glucagon levels were normalised, and marked suppression of glucagon was noted after intravenous glucose. Six months later the arginine test was repeated, but this time the glucagon values were again pathologically increased, and arginine did not stimulate glucagon secretion. The patient is now being evaluated for recurrence of his tumour. The dermatosis has not reappeared.

Patient 2 had normal concentrations of plasma glucagon postoperatively, but glucose tolerance was impaired ( $\mathrm{K}_{\mathrm{g}} 1.35$ to 1.09$)$; basal blood glucose was normal. Glucagon values were suppressed by intravenous glucose. Compared to the preoperative results the insulin response to glucose was much smaller in spite of an increased glycaemic stimulus. In 
this patient the insulin tolerance test was repeated and judged by the glucose values, the tolerance to intravenous insulin was unchanged after the operation; there was a slight increase in glucagon concentrations in response to hypoglycaemia (from 34 to $44 \mathrm{pmol} / 1)$.

Patient 3 also showed normal plasma glucagon values, and responded with suppression of glucagon secretion to the glucose tolerance test, and with stimulation during arginine infusion. The hyperglycaemia in the fasting state, however, remained unchanged, and glucose tolerance was not improved $\left(\mathrm{K}_{\mathrm{g}}=0.72\right)$. The insulin response to intravenous glucose was sluggish and late.

Patient 4 had normal basal levels of glucose, glucagon, and insulin.

\section{Discussion}

The diagnostic functional tests described above were carried out to investigate possible peculiarities in the secretion of insulin and glucagon in patients with glucagon-producing tumours. If abnormal results were encountered, they might be interpreted as signs of autonomy of secretion. The finding of a similar pattern of secretion might be helpful in the diagnosis of borderline cases, e. g. cases with only moderately elevated concentrations of plasma glucagon, which would not be diagnostic per se (e. g. as found in diabetes mellitus [21] or renal failure [22]). Lack of suppression of glucagon secretion by glucose may be found as in two of our patients, but an identical lack of suppressibility is likely to be found in mild as well as severe diabetes mellitus [21].

Arginine infusion stimulated glucagon secretion in three patients, but was without consistent effect in the fourth. The lack of effect of arginine is probably a sensitive sign of pathological $\alpha$-cell function, since all normal subjects [23] respond with at least a doubling of the peripheral concentration of glucagon. Diabetics show hyperresponsiveness to arginine [21]. The lack of effect of arginine is therefore highly suggestive of autonomous secretion of glucagon and supports the suspicion of a glucagonoma. On the other hand, most glucagonoma patients including our cases 2 to 4 , respond actively to arginine $[6,7]$ and the test is therefore a poor predictor of an $\alpha$-cell tumour. Somatostatin suppresses glucagon secretion in man [24]. Lack of suppressibility with somatostatin would be highly suggestive of pathological $\alpha$-cell function. In patients with a glucagonoma, however, somatostatin may be as effective as in normal man $[7,25]$. This was confirmed in the present study.

Very low levels of circulating amino acids have been reported in a number of glucagonoma patients
[2] and were also found in our 4 patients (Table 2). The hypoaminoacidaemia is probably a direct consequence of glucagon hypersecretion. In normal subjects the blood levels of amino acids are very sensitive to even small elevations in glucagon concentration induced by infusion and maintained for several days [26]. This seems to one of the few chronic effects of hyperglucagonaemia, the hyperglycaemic effect of which is evanescent [24].

The intravenous injection of $1 \mathrm{mg}$ of glucagon to patients 1 and 4 gave a completely normal hyperglycaemic response. This shows that the glycogen stores in the liver of these patients were normal, and that the responsiveness of the liver to glucagon was also undiminished in spite of persistent hyperglucagonaemia. These findings suggest that the sensitivity of the liver to glucagon has been set to a new level corresponding to the hyperglucagonaemia, socalled down-regulation [27]. Further elevation of the glucagon concentration in plasma (1 $\mathrm{mg}$ of glucagon intravenously raises the plasma concentration of glucagon well above $10,000 \mathrm{pmol} / \mathrm{l}$ ) can then cause a normal hyperglycaemic response.

The elimination of extreme hyperglucagonaemia in our patients was without consistent effect on glucose tolerance. The improvement of glucose tolerance of patient 1 , which is in agreement with the results of Lightman and Bloom [28], contrasts strikingly to the postoperative impairment noted in patient 2 who had, like patient 4 , a normal $\mathrm{K}_{\mathrm{g}}$-value preoperatively. An explanation for the postoperative impairment of the glucose tolerance of patient 2 might be sought in the marked reduction of the insulin response to glucose postoperatively (as a possible consequence of reduced glucagon-stimulation). A similar reduction was noted, however, in patient 1 whose glucose tolerance was improved. The insulin responses of patient 3 were small and unaffected by the operation, and may well be the cause of his glucose intolerance which was equally unaffected by the operation. The unchanged sensitivity to insulin of patient 2 after the operation also points to the surprisingly inconspicuous effect of hyperglucagonaemia on glucose homeostasis in these patients.

Most, perhaps all, of the glucagon-producing tumours of the pancreas are malignant although slow growing [29]. The earliest possible diagnosis is therefore essential for adequate treatment of these patients. Unfortunately, the only clinical pointer to the diagnosis still seems to be the necrolytic migratory erythema, which is probably a late symptom. All the other components of the syndrome are either non-specific (mild glucose intolerance, anaemia, raised erythrocyte sedimentation rate, weight loss) or unlikely to be encountered by routine screening (hyperglucagonaemia and hypoaminoacidaemia). 
Our results suggest, however, that determination of single amino acids (e. g. alanine) may be helpful in suspected cases with atypical dermatosis [30] or only slightly elevated glucagon levels, whereas none of the tests described here are likely to be of any value. If amino acid and glucagon determinations support the diagnosis, the site of glucagon production may be disclosed by selective pancreatic vein catheterisation with sampling of blood for glucagon determination by which a possible tumour may be precisely located $[18,19]$. This procedure, as illustrated by our patient No. 1, may also be of value in the postoperative follow-up, since recurrences may be disclosed early and localised to facilitate surgical intervention.

\section{References}

1. McGavran, M. H., Unger, R. H., Recant, L., Polk, H. C., Kilo, C., Levin, M. E.: A glucagon-secreting alpha-cell carcinoma of the pancreas. N. Engl. J. Med. 274, 1408-1413 (1966)

2. Mallinson, C.N., Bloom, S.R., Warin, A.P., Salmon, P.R., Cox, B.: A glucagonoma syndrome. Lancet 1974 II, 1-5

3. Binnick, A. N., Spencer, S. K., Dennison, W. L., Horton, E. S.: Glucagonoma syndrome. Report of two cases and literature review. Arch. Dermatol. 113, 749-754 (1977)

4. Bloom, S. R.: Glucagonomas and skin disease. In: Endocrinology. Proceedings of the 5th International Congress of Endocrinology. James, V. H. T. (ed.), Congress Series No.402, vol. 2, pp. 350-352. Amsterdam: Excerpta Medica 1977

5. Holst, J. J.: Glucagonomas. In: Guthormones. Bloom, S. R. (ed.), pp. 599-604. Edinburgh: Churchill Livingstone 1977

6. Tiengo, A., Fedele, D., Marchiori, E., Nosadini, R., Muggeo, M.: Suppression and stimulation mechanisms controlling glucagon secretion in a case of islet-cell tumour producing glucagon; insulin and gastrin. Diabetes 25, 408-412 (1976)

7. Boden, G., Owen, O., Rezvani, I., Elfenbein, B. I., Quickel, K. E.: An islet cell carcinoma containing glucagon and insulin. Diabetes 26, 128-137 (1977)

8. Bang Pedersen, N., Johnsson, L., Holst, J. J.: Necrolytic migratory erythema and glucagon cell tumour of the pancreas: The glucagonoma syndrome. Acta Derm. Venereol. (Stockh.) 56, 391-395 (1976)

9. von Schenck, H., Thorell, J. I., Berg, J., Bojs, G., Dymling, J. F., Hallengren, B., Ljungberg, O., Tibblin, S.: Metabolic studies and glucagon gel filtration pattern before and after surgery in a case of glucagonoma syndrome. Acta Med. Scand. 205, 155-162 (1979)

10. Helland, S., Thorsen, E., Holst, J. J., Ingemansson, S.: The glucagonoma syndrome - necrolytic migratory erythema. A case. T. Norsk Laegeforen (in press)

11. Wilkinson, D.S.: Necrolytic migratory erythema with carcinoma of the pancreas. Trans. St. Johns Hosp. Dermatol. Soc. 59, 244-250 (1973)

12. Sweet, R.D.: A dermatosis specifically associated with a tumour of pancreatic alpha cells. Br. J. Dermatol. 90, 301-308 (1974)

13. Holst, J. J., Christiansen, J., Kühl, C.: The enteroglucagon response to intrajejunal infusion of glucose triglycerides and sodium chloride and its relation to jejunal inhibition of gastric acid secretion in man. Scand. J. Gastroenterol. 11, 297-304 (1976)

14. Holst, J. J., Kreutzfeldt, M., Holm, G., Jensen, E., Poulsen, J. S. D., Sparsø, Brigitte, Sparsø, B., Schmidt, A.: Absence of true pancreatic glucagon but persistence of circulating pancreatic glucagon-like immunoreactivity after pancreatectomy in pigs. Diabéte Metab. 4, 75-79 (1978)
15. von Schenck, H.: Production and characterization of an antiserum against pancreatic glucagon. Clin. Chim. Acta 80, 455-460 (1977)

16. Albano, J.D. M., Ekins, R. P., Maritz, G., Turner, A. C.: A sensitive, precise radioimmunoassay of serum insulin relying on charcoal separation of bound and free hormone moieties. Acta Endocrinol. (Kbh.) 70, 487-509 (1972)

17. Valverde, I., Villanueva, M. L., Lozano, I., Marco, J.: Presence of glucagon immunoreactivity in the glubulin fraction of human plasma ("big plasma glucagon"). J. Clin. Endocrinol. Metab. 39, 1090-1098 (1974)

18. Ingemansson, S., Lunderquist, A., Holst, J. J.: Selective catheterization of the pancreatic vein for radioimmunoassay in glucagon-secreting carcinoma of the pancreas. Radiology 119 , $555-56$ (1976)

19. Ingemansson, S., Holst, J. J., Larsson, L.-I., Lunderquist, A.: Localization of glucagonomas by pancreas vein catheterization and glucagon assay. Surg. .Gynecol. Obstet. 145, 509-516 (1977)

20. Lundbaek, K.: Intravenous glucose tolerance as a tool in definition and diagnosis of diabetes mellitus. Br. Med. J. $1962 \mathrm{VI}$, $1507-1513$

21. Aguilar-Parada, E., Eisentraut, A. M., Unger, R. H.: Pancreatic glucagon secretion in normal and diabetic subjects. Am. $\mathrm{J}$ Med. Sci. 257, 415-419 (1969)

22. Bilbrey, G. L., Faloona, G. R., White, M. F., Knochel, J. P., Borrotto, J.: Hyperglucagonemia of renal failure. J. Clin. Invest. 53, 841-847 (1974)

23. Unger, R. H.: Clinical evaluation of glucagon excess and deficiency. In: Methods in investigative and diagnostic endocrinology. Berson, S. A., Yalow, R. S. (eds.), Part III, vol. 2B, pp. 937-942. Amsterdam: North-Holland Publishing Company 1973

24. Felig, P., Wahren, J., Sherwin, R., Hendler, R.: Insulin, glucagon and somatostatin in normal physiology and diabetes mellitus. Diabetes 25, 1091-1099 (1976)

25. Mortimer, C. H., Carr, D., Lind, T., Bloom, S. R., Mallinson, C. N., Schally, A. V., Tunbridge, W. M. G., Yeomans, L., Coy, D. H., Kastin, A., Besser, G. M., Hall, R.: Effects of growthhormone release-inhibiting hormone on circulating glucagon, insulin and growth hormone in normal, diabetic, acromegalic and hypopituitary patients. Lancet 1974 I, 697-701

26. Marliss, E. B., Aoki, T. T., Unger, R. H., Soeldner, J. Stuart, Cahill, G. F.: Glucagon levels and metabolic effects in fasting man. J. Clin. Invest, 49, 2256-2270 (1970)

27. Soman, W., Felig, P.: Regulation of the glucagon receptor by physiological hyperglucagonaemia. Nature 272, 829-932 (1978)

28. Lightman, S. L., Bloom, S.R.: Cure of insulin-dependent diabetes mellitus by removal of a glucagonoma. Br. Med. J. 1974 I, 367-368

29. Holst, J. J.: Review of the glucagonoma syndrome. Ugeskr. Laeger. 137, 2627-2630 (1975)

30. Holst, J. J.: Possible entries to the diagnosis of a glucagonproducing tumour. In: Diagnosis and localization of gastrointestinal endocrine tumours. Christiansen, L., Nielsen, O.B. Stadil, F., Stage, J. G. (eds.). Scand. J. Gastroenterol. 14, (Suppl.) (1979) (In press)

Received: December 19, 1978, and in revised form: May 14, 1979

\section{J. J. Holst}

Institute of Medical Physiology C

University of Copenhagen

The Panum Institute

Blegdamsvej $3 \mathrm{c}$

DK-2200 Copenhagen N

Denmark 